Part of Journal of Research of the National Bureau of Standards, Volume 23,

October 1939

\title{
ELECTROPHORETIC STUDIES OF WOOL
}

\author{
By Arnold M. Sookne and Milton Harris ${ }^{1}$
}

\section{ABSTRACT}

A new investigation of the electrophoretic properties of wool shows that phthalate ion, used in buffers in earlier work, exhibits a specific ion effect, and shifts the isoelectric point to lower $\mathrm{pH}$ values. In acetate buffers, the isoelectric point of wool scales and cortical cells was found to be at pH 4.5. Samples of ground or powdered wool show an isoelectric point at $\mathrm{pH}$ 4.2. Much of the confusion which exists concerning the location of the isoelectric point has arisen from the assumption that the isoionic and isoelectric points are identical. The significance of both of these points in wool processing is discussed.

\section{CONTENTS}

I. Introduction

II. Materials and methods _...

III. Experiments and discussion..... 474

1. Effect of buffers on the electrophoretic properties of wool _.... 474

2. Electrophoretic properties of cortical cells and scales........ 474

3. Electrophoretic properties of ground and powdered wool_..... 475

IV. Significance of the isoelectric and isoionic points_........... 476

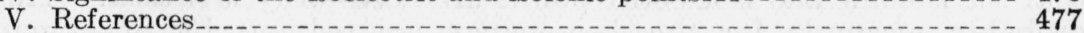

\section{INTRODUCTION}

Electrophoretic measurements have been used for distinguishing protein surfaces $[1,2,3],{ }^{2}$ and for determining one of the characteristic constants of a protein, namely, the isoelectric point.

Considerable disagreement appears to exist concerning the $\mathrm{pH}$ at which wool is isoelectric and the significance of the isoelectric point in wool processing. The chief difficulty arises from the fact that some of the values have been determined by methods which do not necessarily define isoelectric points. In the present paper an attempt is made to clarify this situation. In addition, the results of a new investigation of the electrophoretic properties of wool are presented.

As defined by Abramson [1], the isoelectric state of a surface is that electrical state in which the sum of the positive and negative charges at the surface over a time average is equal to zero. The isoelectric point, then, is defined as the reference concentration of hydrogen ion or some other ion $\left(\mathrm{Th}^{++++}\right.$, for example) at which this condition is found; that is, the condition at which the electric mobility is zero. Although it has become customary to define the isoelectric point in terms of the $\mathrm{pH}$ scale, it must be defined in terms

\footnotetext{
${ }^{1}$ Research Associates at the National Bureau of Standards, representing the Textile Foundation, Inc.
}

2 Figures in brackets indicate the literature references at the end of this paper. 
which include a complete description of the medium in which no migration takes place.

The isoionic point is defined as the point at which dissociable groups of the substance combine equally and only with hydrogen and hydroxyl ions [6]. This is identical with the isoelectric point only when the substance does not combine with ions other than hydrogen or hydroxyl. It follows then that although it may be possible to determine the isoelectric point by several methods, as by titration, provided that the substance combines with only hydrogen or hydroxyl ions, only an electrokinetic method can determine the isoelectric point in every case. The isoionic and isoelectric points of some soluble proteins have been found to be approximately the same. However, in the case of the insoluble materials, especially those which are more or less crystalline in nature, the isoelectric and isoionic points may be far apart. This is true of crystals of even relatively simple substances, such as amino acids [8]. It has been suggested that in addition to the amphoteric properties at the surface, negative ions are also adsorbed at the surface, which results in a shift of the isoelectric point to lower $\mathrm{pH}$ values.

Values for the isoelectric point of wool obtained by a number of investigators are reviewed by Speakman and Stott [4] and for that reason need not be given here. The important fact which should be emphasized is that, with the exception of Harris' earlier value [5], practically all of the values were based either directly or indirectly on determinations of the amount of hydrogen or hydroxyl ion bound by the fiber. The assumption was made that the isoelectric state of a substance is dependent only on the state of its dissociable acid and basic groups (its combination with hydrogen or hydroxyl ions)that the isoionic and isoelectric points are necessarily identical. This probably accounts for the discrepancy pointed out by Speakman and Stott [4] between the figures $\mathrm{pH} 5$ and $\mathrm{pH} 3.4$ for the "isoelectric" point of wool. The former was determined by titration and may therefore be considered as the isoionic point. ${ }^{3}$ The latter was determined by electrophoresis and is therefore the isoelectric point in phthalate buffers. (See below for values in acetate buffers.) Speakman [9] explains the low value determined by electrophoresis as being caused by the presence of - $\mathrm{NH}$ - groups on the surface of the wool. Although we agree that the low value is due to a surface phenomenon, it is hard to see how the kind of groups Speakman postulates could cause a lowering rather than a raising of the $\mathrm{pH}$ value at which the wool is isoelectric.

\section{MATERIALS AND METHODS}

Studies of the electrophoretic properties of wool are complicated by the fact that the fibers have a complex morphological structure. In the present investigation an attempt was made to study the component parts of the fiber. Measurements were made on cortical cells, scales, and what is assumed to be the intracellular substance. The scales were obtained by passing wool fibers through a Koerner grinder [10]. This machine produces very little cutting action, since the blades are about $1 / 16$ inch apart. Microscopic examination of

${ }^{8}$ In an investigation now in progress in this laboratory, it has been found that the point at which com. bination with acid begins is near $\mathrm{pH} 6.4$ [7]. 
fibers so treated indicated considerable descaling, but the bulk of the fibers appeared to be uncut. Examination of the particles removed from the fibers showed them to be plate-like and about 2 microns in size.

Cortical cells were obtained by retting fibers with bacteria and also from the dust in a carpet wear-testing machine ${ }^{4}$ in which the fibers are broken down by mechanical action.

Fibers were also reduced to a convenient particle size by grinding in a laboratory Wiley mill or in a pebble mill. When the former was used, the wool was ground until it passed through a 60-mesh screen. The powder was suspended in water, the larger particles were allowed to settle, and the particles ( 1 to 5 microns) remaining in the supernatant liquid were used for the measurements. Both methods of grinding destroyed the cell structure and presumably exposed the intracellular substance.

For the measurement of the electric mobility of ground-wool particles, an Abramson horizontal microelectrophoresis cell was employed. The apparatus and methods were essentially the same as those described by Moyer [12]. The apparatus was checked from time to time by measuring the mobility of human erythrocytes in $M / 15$ phosphate buffer at pH 7.4 [13]. Either a $20 \times$ ocular and $20 \times$ objective or a $28 \times$ ocular and $40 \times$ water-immersion objective were used.

The mobilities of cortical cells of wool were measured in a vertical microelectrophoresis cell similar to that described by Abramson, Moyer, and Voet [14], since the rapid settling of these large particles made the use of the horizontal cell impossible. In the vertical cell the particle settles in the plane of observation and remains in the same electroosmotic level throughout the measurement. The electric mobility of the particle is the mean of its velocities over a given distance in both directions. The effect of gravitational fall is thus eliminated. When the electric mobility is large compared to the velocity of gravitational fall, the distance traveled in one direction. divided by the mean of the times of transit with the current in both directions gives substantially the same result. In extreme cases (for example, in the immediate neighborhood of the isoelectric point) the electric mobility is very small compared to the gravitational fall, and reversal of the current may even fail to reverse the direction of motion of the particle.

Measurements were made in a constant-temperature room at $25^{\circ} \mathrm{C}$ to avoid convection currents caused by temperature differences. With solutions of ionic strength as low as $0.02 \mathrm{M}$, convection currents were caused by leaving the electric current on for even relatively shor $t$ periods when the vertical cell was used. For this reason, all measurements in the vertical cell were made in solutions of $0.005 M$ ionic strength, and the current was left on for as short a time as possible. The $20 \times$ ocular and $20 \times$ objective were used for all measurements in the vertical cell. The cell was checked against the horizontal cell by measuring identical suspensions of wool in both cells. In general, the vertical cell was found more difficult to use and required more

\footnotetext{
4 The cells were obtained from a sample of undyed carpet which was subjected to a wear test on the Shaw. mut carpet-testing machine. The disintegration of fibers under these conditions into cells has been reported by Schiefer and Oleveland [11].
} 
time for a measurement than the horizontal cell, which is well adapted to measurement of the mobilities of small particles.

$\mathrm{pH}$ values of the suspensions were measured with a MacInnes and Belcher-type glass electrode and a vacuum-tube potentiometer, using a cathode-ray tube as null indicator. The $\mathrm{pH}$ values were referred to potassium acid phthalate, $0.05 \mathrm{M}$, which was assigned a $\mathrm{pH}$ value of 4.01 [15].

\section{EXPERIMENTS AND DISCUSSION}

\section{EFFECT OF BUFFERS ON THE ELECTROPHORETIC PROPERTIES OF WOOL}

In a recent investigation relating to the electrophoretic properties of silk [16], large ions of complex structure, such as phthalate or picrate, appeared to have specific effects which produced appreciable

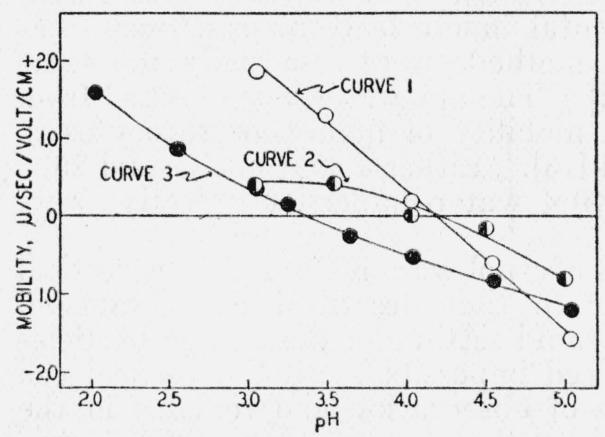

Figure 1.-The electrophoretic mobility in different buffer solutions of wool ground in a Wiley mill.

Curve 1, $0.005 \mathrm{M}$ ionic strength acetic acid-sodium acetate solutions. Curve 2, 0.1 M ionic strength acetic acidsodium acetate solutions. Curve 3, Clark's phthalate buffers.

$M$ ionic strength Under these condition the acetate butrers $\mathrm{pH} 4.2$, a shift of approximately $0.8 \mathrm{pH}$ unit. This shift is of the same order of magnitude as that obtained for silk. Curve 2 shows the results for the same sample in acetic acid-sodium acetate buffers of $0.1 M$ ionic strength and shows that the shift in isoelectric point caused by the use of phthalate buffers is not the result of increased ionic strength but has resulted from a specific ion effect.

\section{ELECTROPHORETIC PROPERTIES OF CORTICAL CELLS AND SCALES}

Figure 2 shows the mobility as a function of $\mathrm{pH}$ in $0.005 \mathrm{M}$ acetic acid-sodium acetate buffers for three different samples of cortical cells and one sample of scales. One sample of the cells was prepared by the mechanical action of the carpet tester on wool. The other samples were prepared by retting the fibers with bacteria for periods of 4 and 14 months. The scales were obtained by subjecting wool fibers to the action of a Koerner grinder, as previously described.

The results, as shown by the curves, indicate that all three samples of cortical cells and the sample of scales have the same electrophoretic properties and are isoelectric at $\mathrm{pH} 4.5$ in the buffer system used. It 
has been suggested by many investigators that an intercellular phase exists between the cortical cells and is removed during prolonged treatment of fibers with certain reagents, such as concentrated ammonia [17], or during retting [18]. If it is assumed that all such material would be removed during the long retting process, but that the cells obtained by mechanical action would still contain some of it, then the only conclusion which may be drawn from the present investigation is that if such a phase exists, it necessarily has the same electrophoretic properties as the cells. Alternative conclusions that the intercellular phase is not completely removed during these treatments or that one

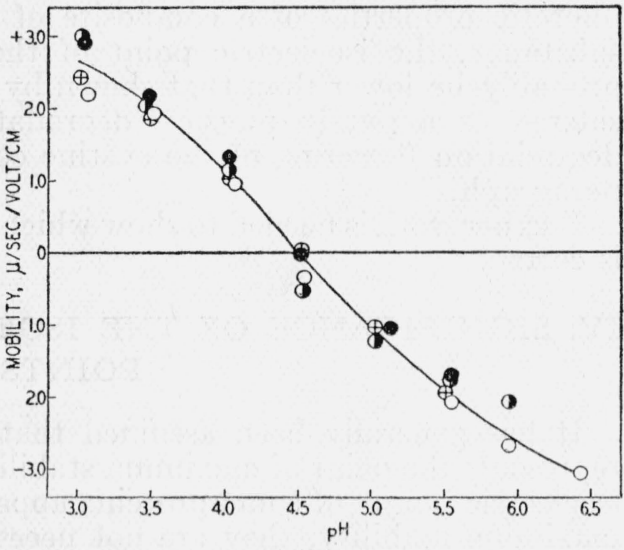

Figure 2.-A comparison of the $p H$-mobility curves of wool scales and three different samples of cortical cells in acetic acid-sodium acetate solutions of $0.005 \mathrm{M}$ ionic strength.

Scales prepared by grinding wool in Koerner machine, $\oplus$; cortical cells obtained by retting wool with bacteria for 4 months, 14 , and for 14 months, ; and cortical cells prepared by grinding wool in a carpet-testing machine, $\mathrm{O}$. does not exist are obviously not eliminated by these results.

\section{ELECTROPHORETIC PROPERTIES OF GROUND AND POWDERED WOOL}

Figure 3 shows the pH-mobility curve for samples ground in a laboratory Wiley mill and in a ball mill. The dotted curve is the

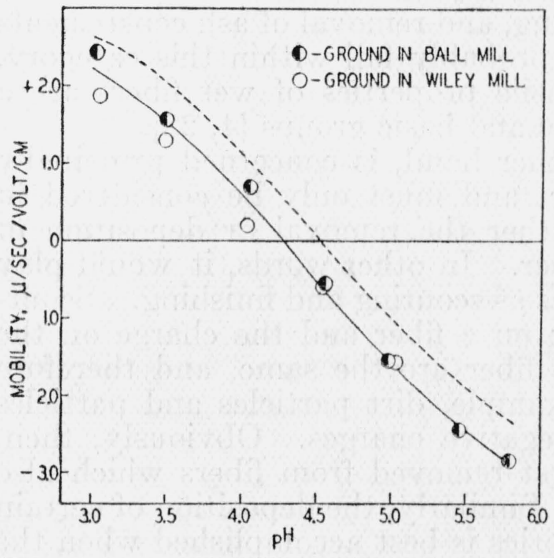

Figure 3.-A comparison of the $p H$ mobility curves in $0.005 \mathrm{M}$ ionic strength acetic acid-sodium acetate buffers of wool ground in ball mill and Wiley mill.

The broken line, identical with the smooth curve of figure 2, is included for comparison. curve taken from figure 2 . It has been shown elsewhere [19] and in this laboratory that the action of the ball mill results in a lowering of the cystine content of wool, which suggests that the shift in the curve to lower $\mathrm{pH}$ values may have resulted from such degradation. It would appear, however, that the action of the Wiley mill is much less drastic. When fibers were ground in this mill and tested without separation into sizes, no degradation was found. However, this cannot be regarded as proof that the smaller particles were not degraded. The proportion of fine particles is small, so that even if they were highly degraded, it is probable that the effect on the entire mass would not be measurable.

Another explanation for the shift of the curve is that the cortical 
cells may be ruptured by the grinding with consequent exposure of an intracellular substance. Since the curve in figure 3 shows the electrophoretic properties of a composite of scales, cells, and intracellular substance, the isoelectric point of the last substance alone would probably be lower than that shown by the curve. This may be considered as a purely physical degradation rather than the chemical degradation (lowering of the cystine content) noted in the preceding paragraph.

Further work is needed to show which, if either, of these explanations is correct. Sists

\section{SIGNIFICANCE OF THE ISOELECTRIC AND ISOIONIC POINTS}

It has generally been assumed that the isoelectric point of wool represents the point of maximum stability of the fiber. Although the isoelectric points of some proteins appear to be close to the points of maximum stability, they are not necessarily the same. Actually, it is possible for the stability region of a protein to be far from the isoelectric point [20]. Whether the point of maximum stability will be at or near the isoelectric point will depend upon the reactivity of specific linkages in the molecules. For example, assume that a protein containing disulfide linkages from the amino acid cystine has an isoelectric point in the alkaline region as a consequence of a high content of either lysine or arginine. In view of the known instability of disulfides in even weakly alkaline solutions, it is very unlikely that the point of maximum stability of such a substance would be located near its isoelectric point.

The concept of the isoelectric and isoionic points can be utilized in practical wool processing. Since the isoionic point involves only the acidic and basic properties of the fiber, it should be considered in studying such wool processes as are related to these properties. Dyeing with soluble dyes [21], felting, and removal of ash constituents from the fiber are processes that probably fall within this category. In addition, the swelling and tensile properties of wet fibers are a function of the state of their acidic and basic groups [4, 22].

The isoelectric point, on the other hand, is concerned principally with the total net surface charge, and must only be considered in relation to processes involving either the removal or deposition of materials on the surface of the fiber. In other words, it would play an important part in such processes as scouring and finishing. Scouring is facilitated when the charge on a fiber and the charge on the material being removed from the fiber are the same, and therefore tend to repel each other. For example, dirt particles and particles of most inert substances carry negative charges. Obviously, then, such macroscopic particles are best removed from fibers which also have a large net negative charge. Similarly, the deposition of certain finishing materials on fibers or fabrics is best accomplished when the charges on the fibers and material to be deposited are of opposite sign. Although the dyeing problem is undoubtedly more complicated, it is probable that dyeing with colloidal dyes is related to the isoelectric point. 


\section{REFERENCES}

[1] H. A. Abramson, Electrokinetic Phenomena (The Chemical Catalog Co., New York, N. Y., 1934).

[2] H. A. Abramson, Cold Spring Harbor Symposia Quant. Biol. 1, 39 (1933).

[3] L. S. Moyer, Cold Spring Harbor Symposia Quant. Biol. 6, 228 (1938).

[4] J. B. Speakman and E. Stott, Trans. Faraday Soc. 30, 539 (1934).

[5] M. Harris, BS J. Research 8, 779 (1932) RP451; Am. Dyestuff Reptr. 21, 399 (1932).

[6] S. P. L. Sørenson, K. Linderstrøm-Lang, and E. Lund, J. Gen. Physiol. 8, $543(1927)$.

[7] J. Steinhardt and M. Harris, in preparation for publication.

[8] H. A. Abramson and L. S. Moyer, J. Gen. Physiol. 21, 729 (1938).

[9] J. B. Speakman and E. Stott, Trans. Faraday Soc. 31, 1425 (1935).

[10] J. O. Burton and R. H. Rasch, BS J. Research 6, 603 (1931) RP295.

[11] H. F. Schiefer and R. S. Cleveland, BS J. Research 1\%, 155 (1934) RP640.

[12] L. S. Moyer, J. Bact. 31, 531 (1936).

[13] H. A. Abramson, J. Gen. Physiol. 12, 711 (1929).

[14] H. A. Abramson, L. S. Moyer, and A. Voet, J. Am. Chem. Soc. 58, 2362 (1936).

[15] D. I. Hitcheock and A. C. Taylor, J. Am. Chem. Soc. 60, 2710 (1938).

[16] A. M. Sookne and M. Harris, J. Research NBS 23, 299 (1939) RP1234.

[17] R. Haller and F. W. Holl, Kolloid-Z. 75, 212 (1936).

[18] E. D. Stakheeva-Kaverzneva and N. I. Gavrilov, Bul. soc. chim. (Mém.) 4, 647 (1937); J. B. Speakman and P. R. McMahon, Nature 141, 118 (1938).

[19] J. I. Routh and H. B. Lewis, J. Biol. Chem. 124, 725 (1938).

[20] P. S. Lewis, Biochem. J. 20, 965, 978, 984 (1926); 21, 46 (1927); J. Steinhardt, Kgl. Danske Videnskab. Selskab, Math.-fys. Medd. 14, No. 11, 1 (1937).

[21] A. L. Smith and M. Harris, J. Research NBS 19, 81 (1937) RP1012; Am. Dyestuff Reptr. 26, 416 (1937).

[22] J. B. Speakman, Trans. Faraday Soc. 29, 148 (1933); A. M. Sookne and M. Harris, J. Research NBS 19, 535 (1937) RP1043; Am. Dyestuff Reptr. 26, P659 (1937).

Washington, August 15, 1939. 